\title{
Genetic and Lifestyle Causal Beliefs about Obesity and Associated Diseases among Ethnically Diverse Patients: A Structured Interview Study
}

\author{
S.C. Sanderson ${ }^{a, f}$ M.A. Diefenbach ${ }^{b, f}$ S.A. Streicher ${ }^{g}$ E.W. Jabs ${ }^{a, f}$ \\ M. Smirnoffc,f C.R. Horowitz ${ }^{d, f}$ R. Zinberga,f C. Clesca ${ }^{a} \quad$ L.D. Richardson ${ }^{e, f}$ \\ Departments of ${ }^{\mathrm{a}}$ Genetics and Genomic Sciences, ${ }^{\mathrm{b}}$ Urology, ${ }^{\mathrm{c}}$ Nursing, ${ }^{\mathrm{d}}$ Health Evidence and Policy, \\ eEmergency Medicine, and ${ }^{\mathrm{f}}$ The Charles Bronfman Institute for Personalized Medicine, Mount Sinai School of \\ Medicine, New York, N.Y., and ${ }^{9}$ Yale School of Public Health, Yale University, New Haven, Conn., USA
}

\section{Key Words}

Attitudes $\cdot$ Behavior $\cdot$ Causal beliefs $\cdot$ Community genetics $\cdot$ Complex diseases - Diet • Exercise - Genomics • Obesity • Translational research

\begin{abstract}
Background: New genetic associations with obesity are rapidly being discovered. People's causal beliefs about obesity may influence their obesity-related behaviors. Little is known about genetic compared to lifestyle causal beliefs regarding obesity, and obesity-related diseases, among minority populations. This study examined genetic and lifestyle causal beliefs about obesity and 3 obesity-related diseases among a low-income, ethnically diverse patient sample. Methods: Structured interviews were conducted with patients attending an inner-city hospital outpatient clinic. Participants ( $\mathrm{n}=$ 205) were asked how much they agreed that genetics influence the risk of obesity, type 2 diabetes, heart disease, and cancer. Similar questions were asked regarding lifestyle causal beliefs (overeating, eating certain types of food, chemicals in food, not exercising, smoking). In this study, $48 \%$ of participants were non-Hispanic Black, 29\% Hispanic and $10 \%$ non-Hispanic White. Results: Over two-thirds (69\%)
\end{abstract}

of participants believed genetics cause obesity 'some' or 'a lot', compared to $82 \%$ for type 2 diabetes, $79 \%$ for heart disease and $75 \%$ for cancer. Participants who held genetic causal beliefs about obesity held more lifestyle causal beliefs in total than those who did not hold genetic causal beliefs about obesity (4.0 vs. 3.7 lifestyle causal beliefs, respectively, possible range $0-5, p=0.025$ ). There were few associations between causal beliefs and sociodemographic characteristics. Conclusions: Higher beliefs in genetic causation of obesity and related diseases are not automatically associated with decreased lifestyle beliefs. Future research efforts are needed to determine whether public health messages aimed at reducing obesity and its consequences in racially and ethnically diverse urban communities may benefit from incorporating an acknowledgement of the role of genetics in these conditions.

Copyright $\odot 2012$ S. Karger AG, Basel

\section{Background}

Obesity continues to be a major public health issue, with over two-thirds of the US population being overweight or obese [1]. This chronic condition is caused by

\section{KARGER}

E-Mail karger@karger.com

www.karger.com/phg
(C) 2012 S. Karger AG, Basel

$1662-4246 / 13 / 0163-0083 \$ 38.00 / 0$
Saskia C. Sanderson

Department of Genetics and Genomic Sciences

Mount Sinai School of Medicine

1425 Madison Avenue, New York, NY 10029 (USA)

E-Mail saskia.sanderson@mssm.edu 
multiple environmental, lifestyle and genetic causes. Whilst the obesogenic environment clearly plays an important role in the current obesity epidemic, twin studies suggest that genetic factors explain $50-90 \%$ of the variance in body mass index [2,3]. Recently, the first common gene variant to be associated with common forms of obesity risk was identified in the fat mass and obesityassociated (FTO) gene [4]. Roughly 1 in 6 people are homozygous for the FTO risk allele (i.e. have inherited 2 copies of the 'risky version' of the gene, one each from both of their parents), and these individuals have a 1.7fold increased odds of obesity compared to those with no risk allele. The association has been shown to be robust in multiple populations [5-10]. New genetic associations with obesity are rapidly being discovered $[11,12]$.

As obesity genomics research gains momentum, it is important to assess how the public views the role of genetic causes in obesity. According to Leventhal et al.'s [13, 14] self-regulation framework, causal beliefs about health and illness are potentially important influences on people's lifestyle and health behavior choices. Specifically, self-regulation framework specifies a number of distinct cognitive attributes (i.e. beliefs and expectations) that are related to health behavior choices. Chief among these are causal beliefs. The importance of causal beliefs has been demonstrated in many areas; specifically in the area of genetic testing, previous research has suggested when a disease is believed to have a genetic cause, the perceived importance of lifestyles may be diminished [15]. Given the importance of healthy lifestyles in obesity prevention and treatment, assessing causal beliefs about this condition, as well as its health consequences such as type 2 diabetes, heart disease and some cancers [16, 17], is imperative. Addressing this question will shed light on whether increasing dissemination of information about genomics may potentially have beneficial, harmful or neutral effects on important cognitive mediators of obesity-related behaviors.

Previous research examining causal beliefs relevant to obesity has primarily focused on diseases associated with obesity, such as type 2 diabetes [18-20], heart disease [2124] and cancer [25-27], rather than on obesity itself. To our knowledge, only a handful of recent studies have explored causal beliefs about obesity itself: 2 of these have been among obese patient/clinical populations in Europe $[28,29]$, and 4 with nonclinical populations in the UK [30], Australia [31] and the US [32, 33].

The 4 studies that have examined obesity causal beliefs among nonclinical populations to date have tended to find that people hold stronger beliefs that lifestyles cause obesity rather than genetics. For example, among 3,534 US individuals who completed the 2007 Health Information National Trends Survey (HINTS), 19\% of individuals believed that inheritance has 'a lot' to do with causing obesity, compared to $72 \%$ who indicated that lifestyle behaviors have 'a lot' to do with causing obesity [32].

To our knowledge, no previous studies have explicitly tested the hypothesis that people who hold genetic causal beliefs are less likely than others to hold lifestyle causal beliefs about obesity. In the 2007 HINTS study, the belief that obesity is inherited was associated with lower reported levels of physical activity, and with lower reported levels of fruit and vegetable consumption [32], providing at least cross-sectional evidence of genetic causal beliefs being associated with adverse lifestyle behaviors. Although both genetic and lifestyle causal beliefs were assessed in that study, the relationship between the 2 sets of beliefs was not reported.

It is particularly important to assess health-relevant beliefs among Hispanic and African American populations because these populations are often underrepresented in research on beliefs and attitudes regarding obesity, yet they are disproportionately affected by obesity and its consequences [1]. Only one previous study investigating causal beliefs about obesity has been conducted specifically with a sample of individuals representative of Hispanic and African American populations [33]: 30\% of their participants were non-Hispanic Black and 35\% were Hispanic, whilst only $27 \%$ were non-Hispanic White. Causal beliefs about a person's weight, as well as causal beliefs about heart disease and diabetes, were examined among 971 suburban adult participants recruited through community health centers in Suffolk County of Long Island in New York State: 38\% of participants held strong genetic causal beliefs about body weight, and $68 \%$ held strong behavioral causal beliefs about body weight. Again, whether individuals who held genetic causal beliefs were more or less likely to hold lifestyle causal beliefs than others was not explored [33]. No differences regarding genetic causal beliefs about body weight were detected between racial/ethnic groups [33].

The primary aims of the present study were therefore: (1) to examine genetic causal beliefs about obesity among a low-income, inner-city, racially and ethnically diverse population comprising primarily Hispanic and African American individuals; (2) to examine whether genetic beliefs varied by sociodemographic characteristics within this urban sample; and (3) to examine whether individuals in this community who held genetic causal beliefs about obesity were less likely than others to hold lifestyle 
causal beliefs about obesity. Our secondary aims were to examine genetic and lifestyle causal beliefs about obesityrelated diseases (type 2 diabetes, heart disease and cancer) in the same population.

\section{Methods}

\section{Study Design}

This was a structured interview study conducted with patients attending an outpatient clinic serving East and Central Harlem in New York City. The study was reviewed and approved by the Mount Sinai School of Medicine IRB.

\section{Participants, Recruitment and Procedure}

Participants for this study were recruited from a primary care internal medicine practice at a medical center in New York City between June and September 2010. The practice accepts publically insured, privately insured and uninsured patients. The majority of patients at the clinic are African American or Hispanic; only $10 \%$ are White. Patients were eligible for this study if they spoke English and were 18 years of age or older. First, physicians in the clinic were contacted to notify them of the days recruitment would take place and to check whether there were any patients attending during that time who should not be approached. After their appointments, participating physicians then asked their potentially eligible patients whether they were interested in learning about a study on attitudes towards genetic research and genetic testing. If the patient was interested, a research assistant accompanied them to a private exam room in the clinic and gave the patient further information about the study. If the patient was still interested in participating, they gave informed consent and completed a screener followed by the main structured interview. If the patient did not have time, but was still interested in participating, they gave their name and number and were contacted at a later date to complete the questionnaire. Recruitment was conducted 3-4 days a week by 5 research assistants.

\section{Measures}

Interview items comprised closed- and open-ended questions which were either adapted from published instruments or developed for this study based on focus groups conducted by Project ENGAGE investigators in the same population [34].

Sociodemographic Characteristics. Sociodemographic measures included age, gender, race/ethnicity, household income, and education level.

Health-Related Characteristics. Family history of disease was assessed with 4 questions ('Including those living and deceased were any of your close blood relatives ever told by a health professional that they had obesity [heart disease/type 2 diabetes/cancer]?'); each was followed by, 'If yes, how many relatives?'. Personal history of disease was assessed with 4 questions: 'Have you ever been told by a health professional that you have obesity [heart disease/type 2 diabetes/cancer]?. Self-reported weight status was assessed with the item: 'In your opinion, which of the following do you think best describes your weight?' (response options: 'underweight', 'normal weight', overweight', 'obese').

Genetic Causal Beliefs. Four items were used to assess participants' genetic causal beliefs about obesity and the 3 obesity-relat- ed diseases: 'How much do you think obesity [heart disease/type 2 diabetes/cancer] is inherited through a person's genes?' (response options: not at all/a little/some/a lot).

Lifestyle Causal Beliefs. Lifestyle causal beliefs about obesity and the 3 obesity-related diseases were assessed with the following sets of questions: (1) 'How much do you think that obesity [heart disease/type 2 diabetes/cancer] is caused by overeating?'; (2) 'How much do you think that obesity [heart disease/type 2 diabetes/ cancer] is caused by eating certain types of food?'; (3) 'How much do you think that obesity [heart disease/type 2 diabetes/cancer] is caused by chemicals in some foods?' (we included this as a lifestyle factor because of the frequency with which it was mentioned in the Project ENGAGE focus groups used to develop the survey instrument [34]); (4) 'How much do you think that obesity [heart disease/type 2 diabetes/cancer] is caused by not exercising?'; and (5) 'How much do you think that obesity [heart disease/type 2 diabetes/cancer] is caused by smoking?'. There were 4 response options for each item (not at all/a little/some/a lot).

\section{Statistical Analysis}

First, the data were described using means and standard deviations (continuous variables) and frequencies (categorical variables). For the main analyses, causal beliefs were dichotomized into yes ('some' and 'a lot') and no ('not at all' and 'a little') responses. Chi-squared $\left(\chi^{2}\right)$ tests were used to examine associations between sociodemographic and health-related characteristics with obesity causal beliefs. The relationships between genetic causal belief about obesity and lifestyle causal beliefs about obesity were examined by comparing the mean number of lifestyle causal beliefs between individuals who did versus did not hold genetic causal beliefs about obesity using t-tests. We also explored these relationships using Pearson correlations. The analyses were then repeated for type 2 diabetes, heart disease and cancer. $p$ values of less than 0.05 were considered significant. All statistical analyses were performed using IBM SPSS statistics 19 .

\section{Results}

\section{Sociodemographic and Health-Related Characteristics}

Of 377 individuals who were approached about the study, 205 (54\%) agreed to participate. Table 1 shows the sociodemographic and health-related characteristics of the participants. Nearly half (48\%) were non-Hispanic Black, 29\% were Hispanic and 10\% were non-Hispanic White. This is broadly reflective of the population attending this clinic (pers. communication from a medical assistant in the clinic). Nearly half (49\%) had an annual household income of $<$ USD 20,000, and only $18 \%$ had a Bachelors or advanced degree. Nearly two-thirds (62\%) of participants reported that they were overweight or obese.

\section{Genetic Causal Beliefs about Obesity}

In our study, $69 \%$ of participants held genetic causal beliefs about obesity (33\% and $36 \%$ believed genetics in- 
Table 1. Sociodemographic and health-related characteristics of the 205 participants in the ENGAGE structured interview study in New York City, June-Sept. 2010

\section{Participant}

n

Mean age (SD)

50 (13.2), range $22-85$ years

$\mathrm{Sex}^{\mathrm{a}}$

Female

Male

141

63

Race/ethnicity

Non-Hispanic Black

Non-Hispanic White

Hispanic

Other

Household income ${ }^{\mathrm{b}}$

$<$ USD 20,000

USD 20,000-39,999

$\geq$ USD 40,000

Education $^{\mathrm{c}}$

Less than high school

High school graduate

Some college

Bachelors or advanced degree

Self-reported weight status

Underweight

Normal weight

Overweight

Obese

Personal diagnosis of obesity

Yes

No

Personal diagnosis of type 2 diabetes

Yes

No

Personal diagnosis of heart disease

Yes

No

Personal diagnosis of cancer

Yes

No

Number of close blood relatives with diagnosis of obesity ${ }^{c}$

None

One

Two or more

Number of close blood relatives with diagnosis of type 2 diabetes ${ }^{c}$

None

One

Two or more

Number of close blood relatives with diagnosis of heart disease $\mathrm{d}^{\mathrm{d}}$

None

One

Two or more

Number of close blood relatives with diagnosis of cancer $^{c}$

None

One

Two or more

$\%$

68.8

30.7

47.8

10.2

28.8

13.2

48.8

21.5

18.0

14.3

37.1

29.8

18.0

3.9

34.6

48.3

13.2

29.3

33.2

66.8

18.5

81.5

5.9

93.7

192

57.6

15.1

26.3

$54 \quad 26.3$

${ }^{a}$ Data missing for 1 individual. ${ }^{b}$ Data missing for 24 individuals. ${ }^{c}$ Data missing for 2 individuals. ${ }^{\mathrm{d}}$ Data missing for 5 individuals. 
Table 2. Genetic causal beliefs about obesity and obesity-related diseases among the 205 participants in the ENGAGE structured interview study in New York City, June-Sept. 2010

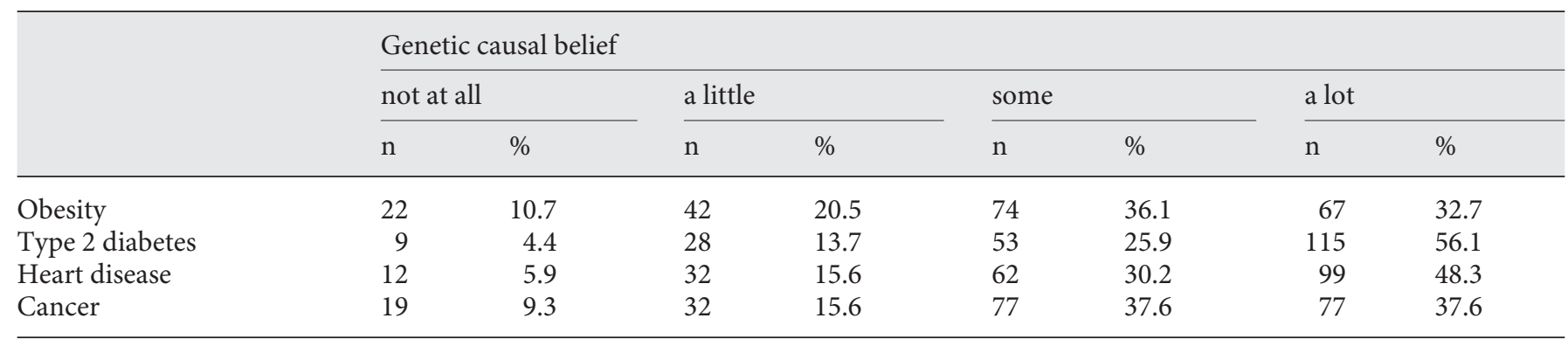

fluence obesity 'a lot' and 'some', respectively; table 2). There were no associations between genetic causal beliefs about obesity (dichotomized into 'a lot'/'some' vs. 'a little'/'not at all') and any sociodemographic or healthrelated characteristics (table 3 ). The mean genetic causal belief score for obesity was $2.91(\mathrm{SD}=0.98$, possible range $=1-4)$.

\section{Lifestyle Causal Beliefs about Obesity}

Figure 1 shows that, when categorized as 'some'/'a lot', $94 \%$ of participants held not exercising causal beliefs, $95 \%$ held overeating causal beliefs, $90 \%$ held eating certain types of food causal beliefs, $70 \%$ held chemicals in food causal beliefs, and $41 \%$ held smoking causal beliefs about obesity, compared to the $69 \%$ who held genetic causal beliefs about obesity. There were few associations between lifestyle causal beliefs about obesity and any of the sociodemographic or health-related characteristics assessed. (online suppl. tables 1-5; for all online suppl. material, see www.karger.com/doi/10.1159/00343793).

\section{Associations between Genetic and Lifestyle Causal \\ Beliefs about Obesity}

In total, the mean number of lifestyle causal beliefs about obesity (possible range $=0-5$ ) held by participants who did versus did not hold genetic causal beliefs about obesity was 4.04 versus 3.68 , respectively ( $\mathrm{p}=0.025$, table 4). When the individual relationships were explored using Pearson correlations, participants who believed obesity is influenced by genetics were more likely than others to believe obesity is also caused by lack of exercise $(\mathrm{r}=0.18, \mathrm{p}=0.011)$, chemicals in food $(\mathrm{r}=0.017, \mathrm{p}=0.015)$ and smoking $(\mathrm{r}=0.196, \mathrm{p}=0.005)$, but no more or less likely to hold overeating or eating certain types of food causal beliefs.
Genetic Causal Beliefs about Obesity-Related Diseases

Overall, $82 \%$ of participants held genetic causal beliefs about type 2 diabetes (fig. 2), 79\% about heart disease (fig. 3) and 75\% about cancer (fig. 4), when categorized as 'some/a lot.' table 3 shows that there were very few associations with participant sociodemographic or health-related characteristics.

\section{Lifestyle Causal Beliefs about Obesity-Related Diseases}

Figures 2 to 4 show the total proportions of participants who believed that each lifestyle influenced type 2 diabetes, heart disease and cancer, respectively, ('some'/'a lot' combined). As these figures show, participants generally held quite strong beliefs that lifestyles caused type 2 diabetes and heart disease, e.g. 77 and $74 \%$ believed that overeating causes type 2 diabetes and heart disease, respectively. In contrast, only $27 \%$ held overeating causal beliefs, 32\% held not exercising causal beliefs and 37\% held eating certain types of food causal beliefs for cancer; the only exception was smoking, which was endorsed by $95 \%$ of participants for cancer. (online suppl. tables 1-5 for associations with sociodemographic and health-related characteristics).

\section{Associations between Genetic and Lifestyle Causal Beliefs about Obesity-Related Diseases}

Participants who believed type 2 diabetes is influenced by genetics were more likely than others to believe type 2 diabetes is caused by overeating $(\mathrm{r}=0.214, \mathrm{p}=$ $0.002)$, lack of exercise $(r=0.176, p=0.012)$ and chemicals in food ( $\mathrm{r}=0.227, \mathrm{p}=0.001)$. As table 4 shows, the total mean number of lifestyle causal beliefs about type 2 diabetes held by participants who did versus did not hold genetic causal beliefs about type 2 diabetes was 3.69 versus $2.92(\mathrm{p}=0.001)$. 
Table 3. Genetic causal beliefs about obesity and obesity-related diseases by sociodemographic and health-related characteristics of the 205 participants in the ENGAGE structured interview study in New York City, June-Sept. 2010

\begin{tabular}{|c|c|c|c|c|c|c|c|c|c|c|c|c|}
\hline & \multicolumn{3}{|c|}{ Cancer } & \multicolumn{3}{|c|}{ Heart disease } & \multicolumn{3}{|c|}{ Type 2 diabetes } & \multicolumn{3}{|c|}{ Obesity } \\
\hline & \multicolumn{2}{|l|}{ yes } & \multirow[t]{2}{*}{$\mathrm{p}$} & \multicolumn{2}{|l|}{ yes } & \multirow[t]{2}{*}{$\mathrm{p}$} & \multicolumn{2}{|l|}{ yes } & \multirow[t]{2}{*}{$\mathrm{p}$} & \multicolumn{2}{|l|}{ yes } & \multirow[t]{2}{*}{$\mathrm{p}$} \\
\hline & $\mathrm{n}$ & $\%$ & & $\mathrm{n}$ & $\%$ & & $\mathrm{n}$ & $\%$ & & $\mathrm{n}$ & $\%$ & \\
\hline \multicolumn{13}{|l|}{ Age } \\
\hline$\leq 40(\mathrm{n}=48)$ & 33 & 68.8 & 0.671 & 38 & 79.2 & 0.276 & 37 & 77.1 & 0.451 & 31 & 64.6 & 0.843 \\
\hline $41-50(\mathrm{n}=45)$ & 35 & 77.8 & & 40 & 88.9 & & 40 & 88.9 & & 33 & 73.3 & \\
\hline $51-59(\mathrm{n}=57)$ & 44 & 77.2 & & 43 & 75.4 & & 45 & 78.9 & & 39 & 68.4 & \\
\hline$\geq 60(\mathrm{n}=54)$ & 42 & 77.8 & & 40 & 74.1 & & 45 & 83.3 & & 37 & 68.5 & \\
\hline \multicolumn{13}{|l|}{ Gender } \\
\hline Male $(\mathrm{n}=63)$ & 46 & 73.0 & 0.583 & 45 & 71.4 & 0.079 & 50 & 79.4 & 0.536 & 39 & 61.9 & 0.167 \\
\hline Female $(\mathrm{n}=141)$ & 108 & 76.6 & & 116 & 82.3 & & 117 & 83.0 & & 101 & 71.6 & \\
\hline \multicolumn{13}{|l|}{ Race/ethnicity } \\
\hline Non-Hispanic Black $(\mathrm{n}=98)$ & 73 & 74.5 & 0.294 & 76 & 77.6 & 0.291 & 79 & 80.6 & 0.930 & 63 & 64.3 & 0.084 \\
\hline Non-Hispanic White $(\mathrm{n}=21)$ & 19 & 90.5 & & 17 & 81.0 & & 17 & 81.0 & & 12 & 57.1 & \\
\hline Hispanic $(\mathrm{n}=59)$ & 44 & 74.6 & & 50 & 84.7 & & 50 & 84.7 & & 48 & 81.4 & \\
\hline Other $(\mathrm{n}=27)$ & 18 & 66.7 & & 18 & 66.7 & & 22 & 81.5 & & 18 & 66.7 & \\
\hline \multicolumn{13}{|l|}{ Yearly household income } \\
\hline$\leq$ USD $20,000(n=98)$ & 68 & 68.7 & 0.283 & 71 & 72.4 & 0.375 & 64 & 64.4 & 0.747 & 71 & 71.0 & 0.480 \\
\hline $\begin{array}{l}\text { USD 20,000-39,000 } \\
(\mathrm{n}=43)\end{array}$ & 31 & 70.5 & & 32 & 74.4 & & 31 & 72.1 & & 34 & 77.3 & \\
\hline$\geq \mathrm{USD} 40,000$ & 30 & 81.1 & & 21 & 58.3 & & 26 & 72.2 & & 25 & 67.6 & \\
\hline \multicolumn{13}{|l|}{ Education } \\
\hline Less than high school $(\mathrm{n}=29)$ & 21 & 72.4 & 0.888 & 21 & 75.0 & 0.85 & 20 & 69.0 & 0.477 & 19 & 65.5 & 0.666 \\
\hline High school graduate $(\mathrm{n}=75)$ & 59 & 77.6 & & 57 & 77.0 & & 55 & 74.3 & & 55 & 72.4 & \\
\hline Some college $(n=61)$ & 46 & 75.4 & & 41 & 67.2 & & 38 & 63.3 & & 48 & 78.7 & \\
\hline $\begin{array}{l}\text { Bachelors or advanced degree } \\
(\mathrm{n}=37)\end{array}$ & 27 & 73.0 & & 19 & 52.8 & & 23 & 62.2 & & 27 & 73.0 & \\
\hline \multicolumn{13}{|l|}{ Family history* } \\
\hline None & 59 & 68.6 & 0.70 & 54 & 69.2 & 0.040 & 54 & 77.1 & 0.567 & 77 & 65.3 & 0.510 \\
\hline One & 34 & 70.8 & & 42 & 79.2 & & 35 & 83.3 & & 23 & 74.2 & \\
\hline Two or more & 59 & 85.5 & & 60 & 87.0 & & 77 & 84.6 & & 39 & 72.2 & \\
\hline \multicolumn{13}{|l|}{ Self reported weight status } \\
\hline $\begin{array}{l}\text { Underweight/normal weight } \\
(\mathrm{n}=79)\end{array}$ & 55 & 69.6 & 0.15 & 58 & 73.4 & 0.16 & 64 & 81.0 & 0.78 & 51 & 64.6 & 0.30 \\
\hline Overweight/obese $(\mathrm{n}=126)$ & 99 & 78.6 & & 103 & 81.7 & & 104 & 82.5 & & 90 & 71.4 & \\
\hline \multicolumn{13}{|l|}{ Personal diagnosis ${ }^{* *}$} \\
\hline Yes & 11 & 91.7 & 0.169 & 31 & 81.6 & 0.613 & 59 & 86.8 & 0.207 & 43 & 71.7 & 0.566 \\
\hline No & 153 & 75.0 & & 130 & 77.8 & & 109 & 79.6 & & 21 & 98.0 & \\
\hline
\end{tabular}

The data shown here is a response of yes ('a lot', 'some'). The other response was no ('a little', 'not at all').

* Family history of cancer: none $(\mathrm{n}=86)$, one $(\mathrm{n}=48)$, two or more $(\mathrm{n}=69)$; heart disease: none $(\mathrm{n}=78)$, one $(\mathrm{n}=53)$, two or more $(\mathrm{n}=69)$; type 2 diabetes: none $(n=70)$, one $(n=42)$, two or more $(n=91)$; obesity: none $(n=118)$, one $(n=31)$, two or more $(n=54)$. ** Personal history of cancer: yes $(n=12)$, no $(n=192)$; heart disease: yes $(n=38)$, no $(n=167)$; type 2 diabetes: yes $(n=68)$, no $(n=137)$; obesity: yes $(n=60)$, no $(n=145)$. Note: significant values are highlighted in bold font.

Table 4. Total number of lifestyle causal beliefs held compared between participants who did versus did not hold genetic causal beliefs: The ENGAGE structured interview study with 205 participants in New York City, June-Sept. 2010

\begin{tabular}{|c|c|c|c|c|c|c|c|c|c|c|c|c|}
\hline Genetic causal belief & $\mathrm{n}$ & $\begin{array}{l}\text { mean } \\
(\mathrm{SD})\end{array}$ & $\mathrm{p}$ & $\mathrm{n}$ & $\begin{array}{l}\text { mean } \\
(\mathrm{SD})\end{array}$ & $\mathrm{p}$ & $\mathrm{n}$ & $\begin{array}{l}\text { mean } \\
(\mathrm{SD})\end{array}$ & $\mathrm{p}$ & $\mathrm{n}$ & $\begin{array}{l}\text { mean } \\
(\mathrm{SD})\end{array}$ & $\mathrm{p}$ \\
\hline Yes ('a lot'/'some’) & 141 & $\begin{array}{l}4.04 \\
(0.97)\end{array}$ & 0.025 & 168 & $\begin{array}{l}3.69 \\
(1.23)\end{array}$ & 0.001 & 161 & $\begin{array}{l}4.05 \\
(1.11)\end{array}$ & 0.082 & 154 & $\begin{array}{l}2.73 \\
(1.42)\end{array}$ & 0.052 \\
\hline No ('a little'/'not at all') & 64 & $\begin{array}{l}3.68 \\
(1.12)\end{array}$ & & 37 & $\begin{array}{l}2.92 \\
(1.38)\end{array}$ & & 44 & $\begin{array}{l}3.70 \\
(1.32)\end{array}$ & & 51 & $\begin{array}{l}2.29 \\
(1.24)\end{array}$ & \\
\hline
\end{tabular}


Fig. 1. Genetic and lifestyle causal beliefs about obesity among the 205 participants in the ENGAGE structured interview study in New York City, June-Sept. 2010 (values represent 'some'/'a lot').

Fig. 2. Genetic and lifestyle causal beliefs about type 2 diabetes among the 205 participants in the ENGAGE structured interview study in New York City, June-Sept. 2010 (values represent 'some'/'a lot').

Fig. 3. Genetic and lifestyle causal beliefs about heart disease among the 205 participants in the ENGAGE structured interview study in New York City, June-Sept. 2010 (values represent 'some'/'a lot').
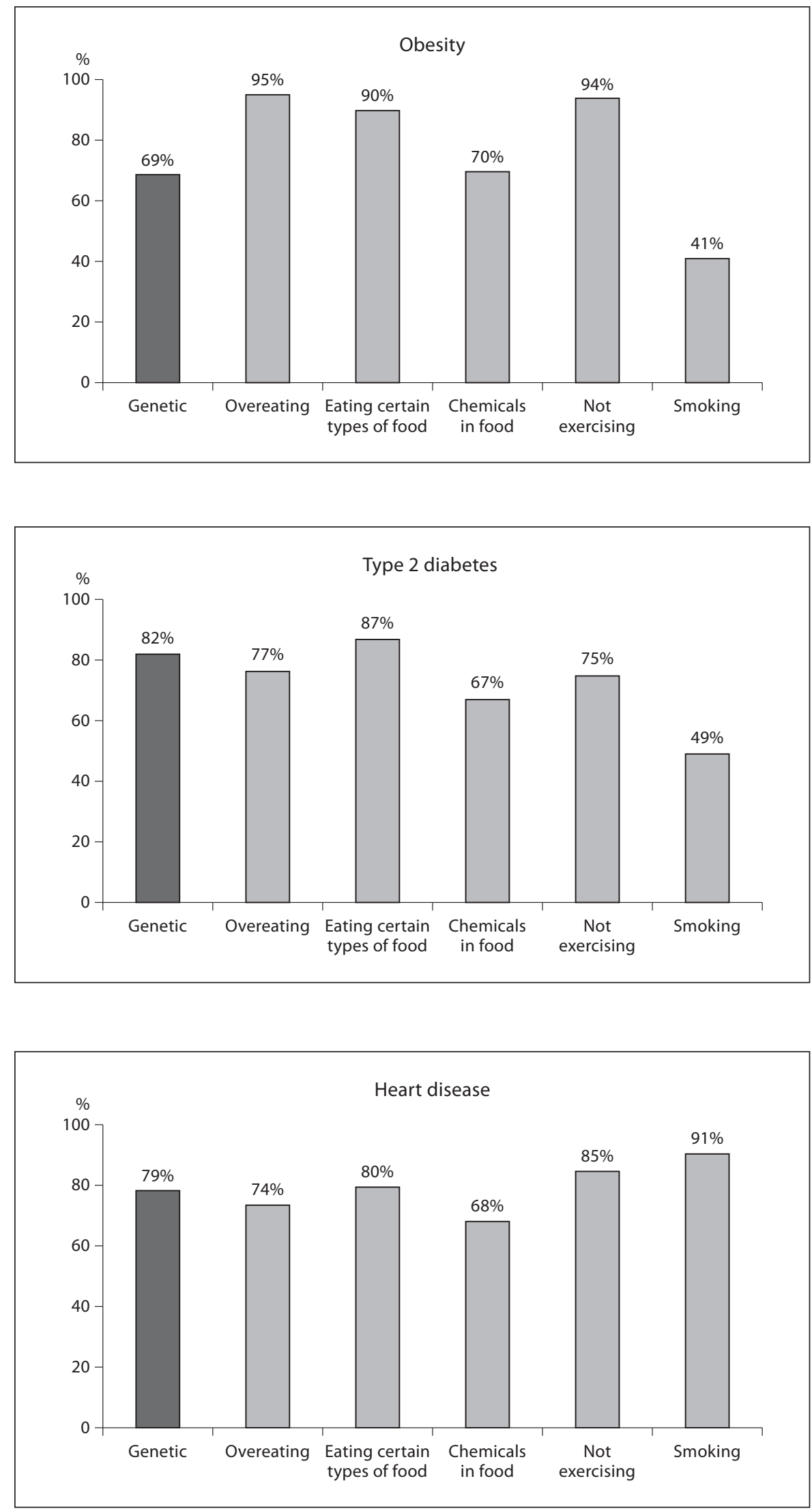

Genetic and Lifestyle Causal Beliefs among Diverse Patients
Public Health Genomics 2013;16:83-93 DOI: $10.1159 / 000343793$ 
Fig. 4. Genetic and lifestyle causal beliefs about cancer among the 205 participants in the ENGAGE structured interview study in New York City, June-Sept. 2010 (values represent 'some'/'a lot').

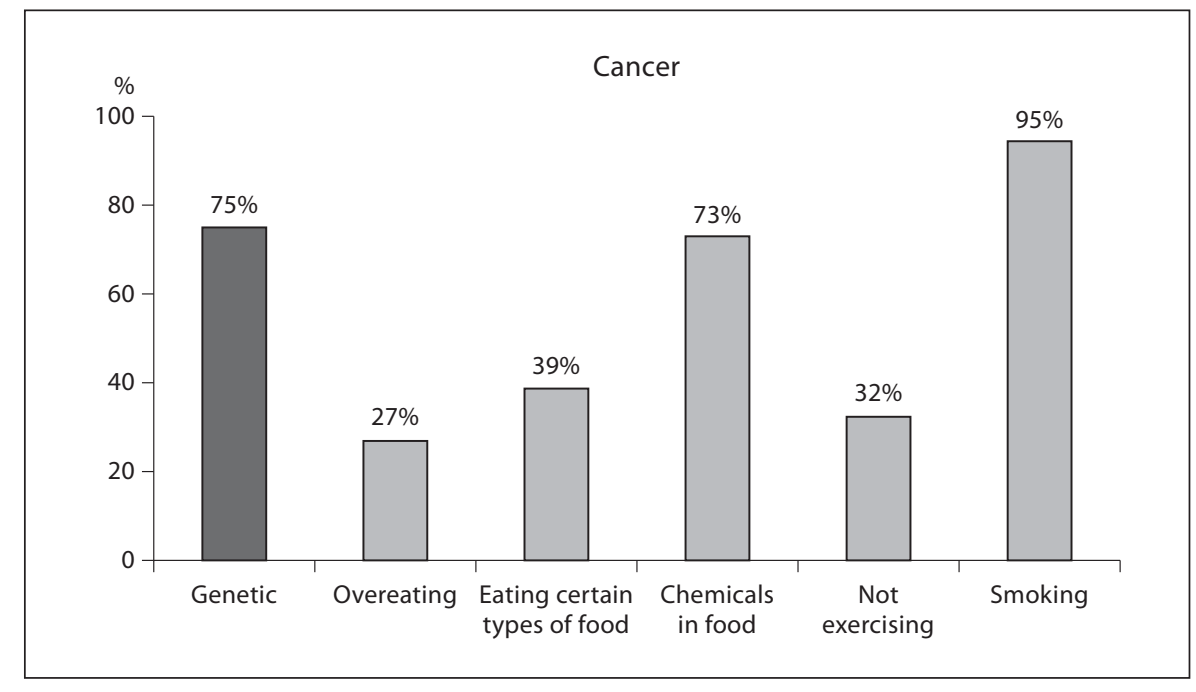

There were no associations between genetic causal beliefs and any of the lifestyle causal beliefs about heart disease. The mean number of lifestyle causal beliefs about heart disease held by participants who did versus did not hold genetic causal beliefs about heart disease was 4.05 versus $3.70(\mathrm{p}=0.082)$.

Participants who believed cancer is influenced by genetics were more likely than others to believe cancer is caused by overeating $(r=0.208, p=0.003)$ and eating certain types of food $(\mathrm{r}=0.194, \mathrm{p}=0.006)$. The mean number of lifestyle causal beliefs about cancer held by participants who did versus did not hold genetic causal beliefs about cancer was 2.73 versus $2.29(\mathrm{p}=0.052)$.

\section{Discussion}

In this study of predominantly Hispanic and African American outpatients at an inner-city hospital clinic, nearly two-thirds of whom self-reported as being overweight or obese, we found that 1 in 3 participants believed that obesity is inherited 'a lot' through a person's genes. This is higher than reported levels in the national HINTS survey in which only $19 \%$ of respondents believed inheritance has 'a lot' to do with causing obesity [32], but similar to the results of a recent study of racially diverse individuals recruited from suburban community health centers in eastern Long Island, in which $38 \%$ of participants held strong genetic causal beliefs about body weight [33]. One possible explanation for this is that in both our study and the Long Island study the genetic causal belief question wording explicitly referred to obesity being in- fluenced by 'genes', whereas the HINTS study referred only to obesity being 'inherited', although why this might lead to higher endorsement is not clear and requires further exploration.

Our findings contribute to growing evidence that people believe that obesity has at least something of a genetic component. This is important because public health messages aimed at reducing obesity almost invariably emphasize the behavioral aspects of obesity (diet and exercise), whilst rarely mentioning genetic factors. However, models of health behavior such as Leventhal et al.'s [13, 14] self-regulation framework of health and illness, and models of persuasiveness, suggest that people are more likely to accept a persuasive health message if there is a 'fit' between the message and their pre-existing beliefs about disease (obesity) causation. Thus, our findings suggest that, for some people, public health messages may be more persuasive if the messages acknowledge the genetic components of obesity because at least some people may be more likely to attend to, accept and be persuaded by this type of message than messages which ignore this important aspect of body weight etiology.

Somewhat surprisingly, we found no associations between sociodemographic or health-related factors and genetic causal beliefs about obesity in the present study. In previous research, Wang and Coups [32] found that obese individuals were more likely to believe that obesity is inherited than nonobese individuals, and that gender was marginally associated with the belief that obesity is inherited, whilst age and education were not associated with the belief that obesity is inherited. Ashida et al. [33] found that older adults were more likely to hold genetic 
causal beliefs about body weight than younger adults. Brogan and Hevey [28] and Hilbert et al. [29] assessed causal beliefs about obesity in obese patient populations in England and Germany, respectively. Brogan and Hevey [28] found that family history was not believed to be a significant cause of obesity; Hilbert et al. [29] found that women were more likely than men, and those with a family history were more likely than those without, to endorse genetic/biological causation of obesity. The lack of associations in our study may have been due to the relative homogeneity of our sample given that all individuals were recruited locally at a single site.

Consistent with previous studies (e.g. [32]), we found no association between causal beliefs and educational attainment. It would be interesting to investigate whether there are associations with specific aspects of education or understanding, e.g. with having a genetic or scientific background, having an increased understanding of genetics generally, or having an increased understanding of gene-environment interactions in obesity specifically.

We found that people who hold genetic causal beliefs about obesity were more, not less, likely to hold lifestyle causal beliefs about obesity; the pattern was similar for type 2 diabetes, and there were similar trends for cancer and heart disease. Although 2 previous studies have reported on the correlates and levels of genetic and lifestyle causal beliefs about obesity [32, 33], to our knowledge, ours is the first to investigate the relationship between genetic and lifestyle causal beliefs about obesity. Previous studies have found mixed results when assessing the relationship between genetic and behavioral beliefs about other common conditions, particularly heart disease and cancer. One study found that participants who held stronger genetic beliefs about heart disease held weaker behavior causal beliefs [35], while other studies found that participants held multifactorial causal models of heart disease [36, 37]. As in our present study, Sanderson et al. [38] recently found that participants who held genetic causal beliefs about heart disease and cancer were similarly more, not less, likely than others to hold lifestyle causal beliefs. Our findings build on this previous research focused on heart disease and cancer and extend it to obesity, supporting the notion that people do not hold 'either'/'or' beliefs about genetic and behavioral causality of obesity and related diseases. This is important because it suggests that increasing dissemination of information about the role of genetics in obesity may not have adverse effects in terms of diminishing people's beliefs in the role of lifestyles in obesity. However, this hypothesis is clearly based on cross-sectional data: future research is needed

Genetic and Lifestyle Causal Beliefs among Diverse Patients to test this hypothesis in studies in which participants are provided with genetic information about obesity, and the effects on genetic and lifestyle causal beliefs about obesity are examined longitudinally.

Limitations of this study include that this was a local population in a healthcare environment, the small sample size, and the nonprobabilistic sample and lack of sampling frame. The local nature of recruitment means that our findings may not be generalizable to the US population more broadly. Patients were informed that the study was about attitudes towards genetics research and genetic testing prior to deciding whether to participate in the study. This may have led to a biased sample of patients, given those who were less interested in genetics may have chosen not to participate. Participants were also initially informed about the study by participating physicians, and so these physicians may have influenced who was invited to participate in the study and who was not. The physicians were instructed to approach all potentially eligible patients within the given timeframe, but there may have still been some bias in whom they chose to inform about the study. There is no reason to suspect that these design considerations would affect the relationships between genetic and lifestyle causal beliefs observed within participants. However, they do emphasize that this study should be seen as exploratory. The findings need to be replicated in a larger, more representative survey of adults in the general population, e.g. individuals recruited through the HINTS survey.

A nother limitation of this study was that, although we were influenced by Leventhal et al.'s $[13,14]$ self-regulation framework to frame our research questions, we did not use this or any other formal theoretical framework to select our measures and develop our questionnaire items. For example, it would be interesting to assess relationships between genetic and lifestyle causal beliefs to other disease perceptions, such as personal control and consequences. Given the multiple diseases assessed, we were limited in the number of constructs we could measure in this study, but it would be interesting to explore these additional theoretical constructs in future research. Another limitation was that we relied on self-reported weight status rather than actual body mass index based on measured height and weight.

The limitations need to be weighed against the strengths, which include that this is one of the first studies to examine genetic and lifestyle causal beliefs about obesity and related diseases among Hispanic and African American individuals. Given the preponderance of White non-Hispanic individuals represented in both genomics 
research and social and behavioral research on genomics issues, there is a need for more studies in this field to include these often underrepresented racial and ethnic populations. This study makes an important contribution to the literature by including perspectives of Hispanic and African American individuals on issues relevant to genomics and obesity. In addition, although Ashida et al. [33] examined beliefs about heart disease, diabetes and a person's weight, and whilst Sanderson et al. [38] examined beliefs about heart disease and cancer, our study is the first to have addressed causal beliefs about obesity, type 2 diabetes, heart disease, and cancer simultaneously within a single study.

Additional research is needed to test the hypotheses suggested by the cross-sectional results presented here. The findings need to be replicated in a larger, more representative sample of respondents. In addition, longitudinal research could test the hypothesis that acknowledging the role of genetics in obesity and related diseases will not diminish peoples' belief in the importance of lifestyles in these complex conditions. For example, individuals could be randomly assigned to be exposed to obesity prevention or treatment interventions which do or do not include acknowledgement of the role of genetics in obesity. The results from such studies could provide useful data on the potential impact of increasing dissemination of genetics in the role of obesity and related diseases, which could have implications for public health policy. Our findings tentatively suggest the hypothesis that, for some people, public health messages may be more persuasive if the messages acknowledge the genetic components of obesity because at least some people may be more likely to attend to, accept and be persuaded by this type of message than messages which ignore this important aspect of body weight etiology.

In conclusion, this study suggests that people do not hold 'either'/'or' notions of genetic and behavioral causality of obesity and related conditions, but rather hold more nuanced, complex mental models of these conditions. Importantly, we showed this in traditionally underrepresented racial and ethnic groups, specifically Hispanic and African Americans. Further research is needed to assess whether public health messages targeted at reducing obesity in these and other communities will indeed benefit from, or rather be hindered by, greater acknowledgement of the role of genetics in obesity and its health consequences.

\section{Acknowledgements}

This work was supported by the Seed Grant Program of The Charles Bronfman Institute for Personalized Medicine and UL1RR029887 from the National Center for Advancing Translational Sciences, National Institutes of Health. We gratefully acknowledge the assistance of our dedicated interviewers Patria Gerardo, Pauline Johnson, Janice Lam, Natalia Lyons and Sayume Romero, and of Micol Zweig for her assistance with manuscript preparation. Most importantly, we are very grateful to all the individuals who participated in this study.

\section{References}

1 Flegal KM, Carroll MD, Ogden CL, Curtin LR: Prevalence and trends in obesity among US adults, 1999-2008. JAMA 2010; 303:235-241.

- 2 Maes HH, Neale MC, Eaves LJ: Genetic and environmental factors in relative body weight and human adiposity. Behav Genet 1997;27:325-351.

-3 Koeppen-Schomerus G, Spinath FM, Plomin R: Twins and non-twin siblings: different estimates of shared environmental influence in early childhood. Twin Res 2003;6:97-105.

$\checkmark 4$ Frayling TM, Timpson NJ, Weedon MN, Zeggini E, Freathy RM, Lindgren CM, Perry JR, Elliott KS, Lango H, Rayner NW, Shields B, Harries LW, Barrett JC, Ellard S, Groves CJ, Knight B, Patch AM, Ness AR, Ebrahim S, Lawlor DA, Ring SM, Ben-Shlomo Y, Jarvelin MR, Sovio U, Bennett AJ, Melzer D, Ferrucci L, Loos RJ, Barroso I, Wareham NJ, Karpe F, Owen KR, Cardon LR, Walker M, Hitman GA, Palmer CN, Doney AS, Morris AD, Smith GD, Hattersley AT, McCarthy
MI: A common variant in the FTO gene is associated with body mass index and predisposes to childhood and adult obesity. Science 2007;316:889-894.

5 Cha SW, Choi SM, Kim KS, Park BL, Kim JR, Kim JY, Shin HD: Replication of genetic effects of FTO polymorphisms on BMI in a Korean population. Obesity (Silver Spring) 2008;16:2185-2187.

-6 Chang YC, Liu PH, Lee WJ, Chang TJ, Jiang YD, Li HY, Kuo SS, Lee KC, Chuang LM: Common variation in the fat mass and obesity-associated (FTO) gene confers risk of obesity and modulates BMI in the Chinese population. Diabetes 2008;57:2245-2252.

7 Dina C, Meyre D, Gallina S, Durand E, Körner A, Jacobson P, Carlsson LM, Kiess W, Vatin V, Lecoeur C, Delplanque J, Vaillant E, Pattou F, Ruiz J, Weill J, Levy-Marchal C, Horber F, Potoczna N, Hercberg S, Le Stunff C, Bougnères $\mathrm{P}$, Kovacs $\mathrm{P}$, Marre M, Balkau B, Cauchi S, Chèvre JC, Froguel P: Variation in FTO contributes to childhood obesity and severe adult obesity. Nat Genet 2007;39:724-726.

$\checkmark 8$ Hinney A, Nguyen TT, Scherag A, Friedel S, Brönner G, Müller TD, Grallert H, Illig T, Wichmann HE, Rief W, Schäfer H, Hebebrand J: Genome wide association (GWA) study for early onset extreme obesity supports the role of fat mass and obesity associated gene (FTO) variants. Plos One 2007;2:e1361.

$>9$ Hunt SC, Stone S, Xin YP, Scherer CA, Magness CL, Iadonato SP, Hopkins PN, Adams TD: Association of the FTO gene with BMI. Obesity (Silver Spring) 2008;16:902-904.

-10 Scuteri A, Sanna S, Chen WM, Uda M, Albai G, Strait J, Najjar S, Nagaraja R, Orrú M, Usala G, Dei M, Lai S, Maschio A, Busonero F, Mulas A, Ehret GB, Fink AA, Weder AB, Cooper RS, Galan P, Chakravarti A, Schlessinger D, Cao A, Lakatta E, Abecasis GR: Genomewide association scan shows genetic variants in the FTO gene are associated with obesityrelated traits. PLoS Genet 2007;3:1200-1210. 
-11 Loos RJ, Lindgren CM, Li SX, Wheeler E, Zhao JH, Prokopenko I, et al: Common variants near $M C 4 R$ are associated with fat mass, weight and risk of obesity. Nat Genet 2008; 40:768-775.

12 Day FR, Loos RJ: Developments in obesity genetics in the era of genome-wide association studies. J Nutrigenet Nutrigenomics 2011;4:222-238.

13 Leventhal H, Benyamini Y, Brownlee S, Diefenbach M, Leventhal EA, Patrick-Miller L, Robitaille C: Illness representations: theoretical foundations; in Petrie KJ, Weinman JA (eds): Perceptions of Health and Illness. Amsterdam, Harwood Academic Publishers, 1997, vol 2, pp 19-46.

14 Leventhal H, Leventhal EA, Cameron L: Representations, procedures and affect in illness self-regulation: a perceptual-cognitive model; in Baum A, Revenson T, Weinman J (eds): Handbook of Health Psychology. Hillsdale, Lawrence Erlbaum, 2001, vol 3, pp 19-47.

$\checkmark 15$ Marteau TM, Weinman J: Self-regulation and the behavioural response to DNA risk information: a theoretical analysis and framework for future research. Soc Sci Med 2006;62:1360-1368.

-16 Eyre H, Kahn R, Robertson RM, Clark NG, Doyle C, Hong Y, Gansler T, Glynn T, Smith RA, Taubert K, Thun MJ; American Cancer Society; American Diabetes Association; American Heart Association: Preventing cancer, cardiovascular disease, and diabetes: a common agenda for the American Cancer Society, the American Diabetes Association, and the American Heart Association. Stroke 2004;35:1999-2010.

17 Center for Disease Control and Prevention (2011): Obesity and Overweight. Atlanta, GA. http://www.cdc.gov/obesity/ (accessed April 20, 2012).

18 Pijl M, Henneman L, Claassen L, Detmar SB, Nijpels G, Timmermans DR: Family history of diabetes: exploring perceptions of people at risk in the Netherlands. Prev Chronic Dis 2009;6:A54.
19 White P, Smith SM, O’Dowd T: Living with Type 2 diabetes: a family perspective. Diabet Med 2007;24:796-801.

20 Valenzuela GA, Mata JE, Mata AS, Gabali C, Gaona E, Thom D, LeBaron S: Knowledge and beliefs regarding type 2 diabetes mellitus in rural Mexico. Ethn Health 2003;8: 353-360.

21 French D, Maissi E, Marteau T: Causal attributions for heart disease: a systematic review. Psychol and Health 2001;16:77-98.

22 French D, Maissi E, Marteau TM: The purpose of attributing cause: beliefs about the causes of myocardial infarction. Soc Sci Med 2005;60:1411-1421.

23 Murphy B, Worcester M, Higgins R, Le Grande M, Larritt P, Goble A: Causal attributions for coronary heart disease among female cardiac patients. J Cardiopulm Rehabil 2005;25:135-143.

24 Darr A, Astin F, Atkin K: Causal attributions, lifestyle change, and coronary heart disease: illness beliefs of patients of South Asian and European origin living in the United Kingdom. Heart Lung 2008;37:91104.

25 Ricker CN, Hiyama S, Fuentes S, Feldman N, Kumar V, Uman GC, Nedelcu R, Blazer KR, MacDonald DJ, Weitzel JN: Beliefs and interest in cancer risk in an underserved Latino cohort. Prev Med 2007;44:241-245.

26 Lykins EL, Graue LO, Brechting EH, Roach AR, Gochett CG, Andrykowski MA: Beliefs about cancer causation and prevention as a function of personal and family history of cancer: a national, population-based study. Psychooncology 2008;17:967-974.

27 Lipworth W, Davey H, Carter S, Hooker C, Hu W: Beliefs and beyond: what can we learn from qualitative studies of lay people's understandings of cancer risk? Health Expect 2010;13:113-124.

28 Brogan A, Hevey D: The structure of the causal attribution belief network of patients with obesity. Br J Health Psychol 2009; 14: 35-48.

29 Hilbert A, Dierk JM, Conradt M, Schlumberger P, Hinney A, Hebebrand J, Rief W: Causal attributions of obese men and women in genetic testing: implications of genetic/ biological attributions. Psychol Health 2009; 24:749-761.
30 Ogden J, Flanagan Z: Beliefs about the causes and solutions to obesity: a comparison of GPs and lay people. Patient Educ Couns 2008;71:72-78.

31 Molster C, Charles T, Samanek A, O'Leary P: Australian study on public knowledge of human genetics and health. Public Health Genomics 2009;12:84-91.

32 Wang C, Coups EJ: Causal beliefs about obesity and associated health behaviors: results from a population-based survey. Int Behavioral Nutri Phys Act 2010;7:19.

33 Ashida S, Goodman M, Pandya C, Koehly LM, Lachance C, Stafford J, Kaphingst KA: Age differences in genetic knowledge, health literacy and causal beliefs for health conditions. Public Health Genomics 2011;14:307316.

-34 Streicher SA, Sanderson SC, Jabs EW, Diefenbach M, Smirnoff M, Peter I, Horowitz CR, Brenner B, Richardson LD: Reasons for participating and genetic information needs among racially and ethnically diverse biobank participants: a focus group study. J Community Genet 2011;2:153-163.

-35 Senior V, Marteau TM, Peters TJ: Will genetic testing for predisposition for disease result in fatalism? A qualitative study of parents responses to neonatal screening for familial hypercholesterolaemia. Soc Sci Med 1999;48:1857-1860.

36 French D, Marteau T, Senior V, Weinman J: The structure of beliefs about causes of heart attacks: a network analysis. Br J Health Psychol 2002;7:463-479.

- 37 Bates BR, Templeton A, Achter PJ, Harris TM, Condit CM: What does 'a gene for heart disease' mean? A focus group study of public understandings of genetic risk factors. Am J Med Genet A 2003;119A:156-161.

38 Sanderson SC, Waller J, Humphries SE, Wardle J: Public awareness of genetic influence on chronic disease risk: are genetic and lifestyle causal beliefs compatible? Public Health Genomics 2011;14:290-297. 